\title{
Optimization of Process Parameters of Abrasive Water Jet Machining (AWJM) on H13 Hot Die Tool Steel by Grey Relational Analysis
}

\author{
Naidu Naresh Kumar ${ }^{1}$, G. Sharath Kumar ${ }^{2}$, M. shiva Shankar Durga ${ }^{3}$, K. Shruthi ${ }^{4}$, \\ K. Srinivas ${ }^{5^{*}}$ \\ 1,2,3,4 UG Scholars, Department of Mechanical Engineering, JB Institute of Engineering and Technology, \\ Hyderabad, Telangana, India- 500075 \\ ${ }^{5}$ Asst. Professor, Department of Mechanical Engineering, JB Institute of Engineering and Technology, \\ Hyderabad, Telangana, India- 500075
}

*Corresponding Author: K. Srinivas, Assistant Professor, Department of Mechanical Engineering, JB Institute of Engineering and Technology, Hyderabad, Telangana, India - 500075

\begin{abstract}
The hot work applications like extrusion tools, pressure die casting tools, forging dies and stamping dies requires high hardenabilty, excellent wear resistance, high toughness, thermal shock resistance and very high polish. $\mathrm{H}-13$ hot die tool steel commonly used to satisfy these requirements. Because of its high hardness and strength H-13 hot die tool steel cannot be machined through traditional machining processes to achieve high surface finish and tight tolerances.
\end{abstract}

Abrasive Water Jet Machining (AWJM) is employed because of its tight tolerances and high surface finish and faster cut. AWJM can be used for drilling, cutting, deburring, cleaning and etching.

As a part of our work, AWJM of H-13 die tool steel is considered for the study. In this work transverse speed, standoff distance and abrasive flow rate are considered as parameters and their effect on performance measures i.e Metal removal rate (MRR) and surface roughness (SR) are studied through experimental investigation.

Using grey relational analysis considered parameters are optimized for both the combination of maximum MRR and minimum Surface roughness. Grey relational analysis will be applied to generate grey relational grade (GRG) to identify the optimum process parameters. These optimum parameters can be adjusted to improve the performance of AWJM.

Keywords: Abrasive Water Jet Machining, Grey relational analysis, MRR, SR

\section{INTRODUCTION}

Abrasive water jet machining is a nontraditional machining process. It is an extended version of water jet cutting in which the water jet contains abrasive particles such as silicon carbide or aluminium oxide in order to increase the material removal rate (MRR) above that of water jet machining. The narrow cutting stream and computer controlled movement enables this process to produce parts accurately and efficiently. Metallic, non-metallic and composite materials of various thicknesses can be cut by this process. This process is particularly suitable for heat sensitive materials that cannot be machined by processes that produce heat while machining. In this process, high velocity water exiting the jewel creates a vacuum which sucks abrasive from the abrasive line, which mixes with the water in the mixing tube to form a high velocity beam of abrasives. This process works on basic principle of water erosion. In this process, a high speed well concentrated water jet is used to cut the metal. It uses kinetic energy of water particle to erode metal at contact surface. The jet speed is almost $600 \mathrm{~m} / \mathrm{s}$. It does not generate any environmental hazards. For cutting hard materials, abrasive particles are used in water jet. These abrasive particles erode metal from contact surface.

Hot work applications require high strength, wear resistance and high temperature resistance. The steels containing around 5\% $\mathrm{Cr}$ are very hard and tough materials, especially $\mathrm{H} 13$ Hot die tool steel. This steel is widely used in die industry to manufacture forging tools, die casting moulds, extrusion 
dies for glass industry. These applications are possible because this steel is having good hardness, toughness and high working temperature [1]. These applications require high surface finish and this steel is not economical to machine by traditional machining process because of its high hardness and strength, so advanced machining process is used to machine this steel. In advanced machining processes Abrasive Water Jet Machining (AWJM) is used to machine this material, AWJM is having faster cut and it is used to clean the dies and moulds. Because of this Abrasive Water Jet Machining of H-13 Hot die tool steel is considered for the study In machining operation it is important to select machining process perimeters to improve the effectiveness of performance measures. To achieve these optimum process parameters has to be found.

Thilak et al have studied the effect of process parameters such as Water pressure, cutting speed, abrasive flow rate, and standoff distance on Top kerf width, bottom kerf width and kerf ratio. They used Grey relational analysis to optimize the performance measures on abrasive water jet machining of aluminum 6063. They found that water jet pressure plays important role in machining [2].

Farhad Kolahan et al used abrasive water jet machining of 6063-T6 aluminum alloy to optimize input process parameters. They used Taguchi method and regression modeling to optimize nozzle diameter, jet traverse rate, jet pressure and abrasive flow rate for depth of cut. They developed a mathematical equation by using regression analysis in terms of selected input process parameters for depth of cut [3].

Parthiban, S. Sathish and M. Chandrasekaran have done work on the machining of stainless steel AISI 316L by abrasive water jet machining. They considered Abrasive flow rate, cutting speed and stand of distance as input process parameters. They have been used numerical optimization technique to determine optimum process parameters for minimization of kerf width and ANOVA is used to determine the influence of process parameters on kerf width. They found that kerf width is mostly effected by abrasive flow rate.[4]

K. S. Jai Aultrin and M. Dev Anand have studied the effect of input process parameters such as waterjet pressure, rate of abrasive flow, diameter of the orifice, diameter of the nozzle and stand of distance on material removal rate and surface roughness. They considered Aluminum, Copper and Lead alloys for machining by abrasive water jet machine. They have developed mathematical model in terms of input process parameters to predict material removal rate and surface roughness by response surface methodology. They found that the experimental values are closer to the predicted values for all the three materials.[5]

Zoran Jurkovic, Mladen Perinic, Sven Maricic have investigated the effect of process paramers on machining of stainless steel and aluminium alloy by abrasive water jet machine. They used regression modeling technique to generate mathematical model in terms of considered process parameters such as water pressure, abrasive flow rate, traverse rate, stand-of distance, material thickness and type of material to predict surface roughness. They also applied Taguchi technique to optimize selected process parameters to minimize surface roughness.[6]

Mayur C. Patel, Mr. S. B. Patel, Mr. R.H. Patel have studied the effect of input process parameters on machining of Aluminum 6351 T6 by abrasive jet machine. They have considered Traverse speed, Abrasive flow rate, and Standoff distance as input process parameters. They used regression analysis to develop mathematical model for surface roughness and kerf taper angle, ANOVA is applied to determine significance of input process parameters. They found that standoff distance is the most effecting process parameter and low standoff distance is giving low surface roughness. [7]

M. A. Azmir, A.K. Ahsan, A. Rahmah, M.M. Noor and A.A. Aziz used multi optimization technique Grey relational Analysis to optimize input process parameters for minimization of surface roughness at different cutting depths. They consider machining of Kevlar composite laminate as work piece material by abrasive water jet machining. They applied grey relational analysis to determine optimum values for hydraulic pressure, abrasive mass flow rate, standoff distance and traverse rate for minimization of surface roughness at different cutting depths. [8]

The objective of the present work to determine optimum process parameters for minimization of surface roughness and maximization of material removal rate for the machining of H13 hot die tool steel by multi objective optimization technique i.e. Grey Relational Analysis 


\section{MeThOdology}

In this paper Taguchi method along with Grey Relational Analysis (GRA) is applied to optimize input process parameters in the machining of $\mathrm{H}-13$ die tool steel by using Abrasive water jet machining (AWJM). The selected responses are Material removal Rate (MRR) and Surface Roughness (SR). The chosen process parameters are Stand-off distance, Traverse speed and Abrasive flow rate. The chemical composition of the selected material i.e. H-13 die tool steel is given in Table 1. Taguchi method utilizes an orthogonal array, which is a form of fractional factorial design containing a representative set of all possible combination of experimental conditions. Using Taguchi method, a balanced comparison of levels of the process parameters and significant reduction in the total number of required experiments can both be achieved. Grey based Taguchi method is a new method forwarded by Deng Ju-long from China to solve multi response optimization problems. Deng first proposed grey relational analysis in 1982 to fulfill the crucial mathematical criteria for dealing with poor, incomplete and uncertain systems. In recent years grey relational analysis becomes a powerful tool to analyze the processes with multiple performance characteristics. This method provides approaches for analysis and abstract modelling of systems for which the information is limited, incomplete and characterized by random uncertainty. It combines the entire considered performance characteristic (objectives) into a single value that can be used as the single characteristic in optimization problems. To apply this method, input attributes (performance characteristic or objective function) need to be normalized. This process is called grey relational generation (GRG).

\subsection{Taguchi Experimental Design}

Taguchi design of experiment is a powerful analysis tool for modeling and analyzing the influence of control factors on performance characteristics. The most important stage in this method lies in the selection of control factors. Based on the literature survey three parameters viz. stand-off distance, traverse speed and abrasive flow rate each at three levels are considered for the present study. The parameters along with their levels are given in Table 2. The total degree of freedom (DOF) for four factors each at three levels is 8 . Therefore $\mathrm{L} 9$ orthogonal array is selected for experimental design and is shown in Table 3.

In Taguchi method the least variation and the optimal parameters are obtained by mean of the S/N ratio. The higher the $\mathrm{S} / \mathrm{N}$ ratio, the more stable the achievable quality. Depending on the required objective characteristics, there are three types of S/N ratio: the lower-the better, the higher-the-better and the nominal-the-best. The S/N ratio with higher-the-better characteristics for MRR and lower the better characteristics for SR can be calculated using Eq 1 and Eq 2 respectively.

$$
\begin{aligned}
& S / N=\log _{10}(1 / n) \sum_{i=1}^{n} \frac{1}{y_{i j}^{2}} \\
& \mathrm{~S} / \mathrm{N}=-\log _{10}(1 / \mathrm{n}) \sum_{\mathrm{i}=1}^{\mathrm{n}} \mathrm{y}_{\mathrm{ij}}^{2}
\end{aligned}
$$

Where $\mathrm{n}=$ number of replications and; $\mathrm{y}_{\mathrm{ij}}=$ observed response value

Where $i=1,2 \ldots \ldots \ldots . . . n ; j=1,2 \ldots k$.

\subsection{Multi Objective Optimization}

Multi-objective formulations are realistic models for many complex engineering optimization problems. In many real-life problems, objectives under consideration conflict with each other, and optimizing a particular solution with respect to a single objective can result in unacceptable results with respect to the other objectives. A reasonable solution to a multi-objective problem is to investigate a set of solutions, each of which satisfies the objectives at an acceptable level without being dominated by any other solution. They differ primarily from traditional GA by using specialized fitness functions and introducing methods to promote solution diversity.

\subsection{Grey Relational Analysis}

GRA is a multi-objective optimization technique, it uses Taguchi's orthogonal array to conduct the experiments. In GRA number of experiments to be conducted depends on number of process parameters chosen for the study and their levels. Based on number input process parameters and their levels Taguchi's orthogonal array has to be selected. Selection of an appropriate orthogonal array for experiments depends on these items in order of priority: 
1. The number of factors and interactions of interest,

2. The number of levels for the factors of interest.

3. The desired experimental accuracy or cost limitations.

In the present study, three factors Stand-of distance, Traverse Speed and Abrasive flow rate each factor has three-level cutting parameters. The next step is to select an appropriate orthogonal array to fit the specific task. The degrees of freedom for the orthogonal array should be greater than or at least equal to those for the machining parameters. In this study, an L9 orthogonal array is used. This array has three columns and nine rows and it can handle the three-level cutting parameters at most. Therefore, only nine experiments are needed to study the entire cutting factor space using the L9 orthogonal array.

In grey relational analysis, experimental results (MRR and Surface Roughness) are first normalized in the range between zero and one, which is also called the grey relational generation. Next, the grey relational coefficient is calculated from the normalized experimental data. Then, the grey relational grade is computed by averaging the grey relational coefficient corresponding to each process response. The overall evaluation of the multiple process responses is based on the grey relational grade. As a result, optimization of the complicated multiple process responses can be converted into optimization of a single grey relational grade. In other words, the grey relational grade can be treated as the overall evaluation of experimental data for the multi response process.

In the study, a linear data pre processing method for the MRR is the higher the- better and is expressed as

$\mathrm{X}_{\mathrm{i}}(\mathrm{k})=\frac{\mathrm{yi}(\mathrm{k})-\min \mathrm{yi}(\mathrm{k})}{\max y i(k)-\min y i(k)}$

Surface roughness which are the lower-the-better, can be expressed as

$\mathrm{X}_{\mathrm{i}}(\mathrm{k})=\frac{\max \mathrm{yi}(\mathrm{k})-\mathrm{yi}(\mathrm{k})}{\max y i(k)-\min y i(k)}$

Where $x i(k)$ is the value after the grey relational generation, min yi $(k)$ is the smallest value of yi $(k)$ for the kth response, and max yi(k) is the largest value of yi(k) for the kth response.

The definition of the grey relational grade in the grey relational analysis is to show the relational degree between the nine sequences $[\mathrm{x} 0(\mathrm{k})$ and $\mathrm{xi}(\mathrm{k}), \mathrm{I}=1,2, \ldots, 9 ; \mathrm{k}=[1,2, \ldots, 9]$. The grey relational coefficient $r_{i}(k)$ can be calculated as

$\mathrm{r}_{\mathrm{i}}(\mathrm{k})=\frac{\Delta \min +\Psi \Delta \max }{\Delta 0 \mathrm{i}(\mathrm{k})+\Psi \Delta \max }$

Where $\Delta 0 \mathrm{i}=11 \mathrm{X} 0(\mathrm{k})=\mathrm{Xi}(\mathrm{k}) 11=$ difference of the absolute value between $\mathrm{X} 0(\mathrm{k})$ and $\mathrm{Xi}(\mathrm{k})$;

$\Psi=$ distinguishing coefficient ( 0 to1) generally $\Psi=0.5$

$\Delta \min =$ smallest value of $\Delta 0 \mathrm{i}$

$\Delta \max =$ largest value of $\Delta 0 \mathrm{i}$

After averaging the grey relational coefficients, the grey relational grade $\gamma \mathrm{i}$ can be obtained as $\gamma_{\mathrm{i}}=\sum_{i=0}^{n} r i$

Where $n=$ number of process responses. The higher value of the grey relational grade means that the corresponding cutting parameter is closer to optimal. High grey relational grade gives the optimal conditions.

Table1. Composition of H13 hot die tool steel

\begin{tabular}{|c|c|}
\hline Component & Composition \\
\hline Carbon & $0.40 \%$ \\
\hline Silicon & $1.00 \%$ \\
\hline Chromium & $5.30 \%$ \\
\hline Molybdenum & $1.40 \%$ \\
\hline Vanadium & $1.00 \%$ \\
\hline Sulphur & $0.30 \%$ \\
\hline Iron & remaining \\
\hline
\end{tabular}


Optimization of Process Parameters of Abrasive Water Jet Machining (AWJM) on H13 Hot Die Tool Steel by Grey Relational Analysis

Table2. Parameters and Levels

\begin{tabular}{|c|c|c|c|c|c|}
\hline S.No & Parameters & Symbol & Level 1 & Level 2 & Level 3 \\
\hline 1 & Stand-of distance $(\mathrm{mm})$ & $\mathrm{X}_{1}$ & 1 & 2 & 3 \\
\hline 2 & Traverse speed $(\mathrm{mm} / \mathrm{min})$ & $\mathrm{X}_{2}$ & 68 & 76 & 84 \\
\hline 3 & Abrasive flow rate $(\mathrm{g} / \mathrm{min})$ & $\mathrm{X}_{3}$ & 300 & 320 & 340 \\
\hline
\end{tabular}

Table3. L9 Orthogonal Array with Three Factors

\begin{tabular}{|c|c|c|c|}
\hline S.No & $\begin{array}{c}\text { Stand-of distance } \\
(\mathrm{mm})\end{array}$ & $\begin{array}{c}\text { Traverse speed } \\
(\mathrm{mm} / \mathrm{min})\end{array}$ & $\begin{array}{c}\text { Abrasive flow rate } \\
(\mathrm{g} / \mathrm{min})\end{array}$ \\
\hline 1 & 1 & 76 & 300 \\
\hline 2 & 1 & 68 & 320 \\
\hline 3 & 1 & 84 & 340 \\
\hline 4 & 2 & 68 & 320 \\
\hline 5 & 2 & 76 & 340 \\
\hline 6 & 2 & 84 & 300 \\
\hline 7 & 3 & 68 & 340 \\
\hline 8 & 3 & 76 & 300 \\
\hline 9 & 3 & 84 & 320 \\
\hline
\end{tabular}

\section{RESULTS AND DISCUSSION}

Experiments are conducted based on the above experimental arrangement on German Tech S3015 model. Two output responses namely material removal rate and surface roughness have been measured. Observed responses are depicted in Table 4. Work piece material after experimentation as shown in Fig 1.

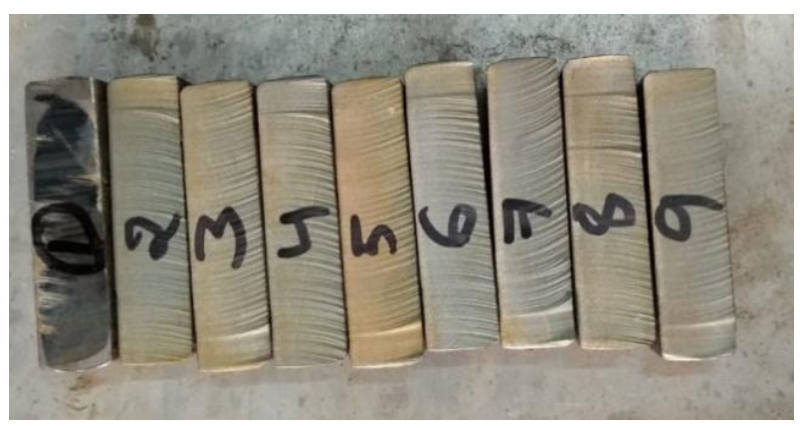

Fig1. Samples after experiments

Table4. Experimental Results

\begin{tabular}{|c|c|c|}
\hline S. No. & MRR & SR \\
\hline 1 & 4.1520 & 3.2160 \\
\hline 2 & 3.2620 & 3.1470 \\
\hline 3 & 2.7800 & 2.1870 \\
\hline 4 & 3.6540 & 3.3500 \\
\hline 5 & 3.8230 & 3.1840 \\
\hline 6 & 4.9390 & 3.5390 \\
\hline 7 & 4.5100 & 3.5130 \\
\hline 8 & 5.9750 & 3.2500 \\
\hline 9 & 4.9510 & 3.7130 \\
\hline
\end{tabular}

After getting experimental results, results are analysed by using grey relational analysis (GRA). GRA consists of determination of normalized values; delta values, grey relational coefficient followed by grey relational grade by using formulae and those values are given in the Table 5, 6, 7 and Table 8 respectively. Figure 2 shows the graph between GRG and Experiment No.

Table5. Normalized values

\begin{tabular}{|c|c|c|}
\hline S.No & MRR & SR \\
\hline 1 & 0.4294 & 0.3257 \\
\hline 2 & 0.1509 & 0.3709 \\
\hline 3 & 0.0000 & 1.0000 \\
\hline
\end{tabular}


Optimization of Process Parameters of Abrasive Water Jet Machining (AWJM) on H13 Hot Die Tool Steel by Grey Relational Analysis

\begin{tabular}{|c|c|c|}
\hline \multicolumn{3}{|c|}{} \\
\hline 4 & 0.2736 & 0.2379 \\
\hline 5 & 0.3264 & 0.3467 \\
\hline 6 & 0.6757 & 0.1140 \\
\hline 7 & 0.5415 & 0.1311 \\
\hline 8 & 1.0000 & 0.3034 \\
\hline 9 & 0.6795 & 0.0000 \\
\hline
\end{tabular}

Table6. $\Delta$ Oi Values

\begin{tabular}{|c|c|c|}
\hline S.No & MRR & SR \\
\hline 1 & 0.5706 & 0.6743 \\
\hline 2 & 0.8491 & 0.6291 \\
\hline 3 & 1.0000 & 0.0000 \\
\hline 4 & 0.7264 & 0.7621 \\
\hline 5 & 0.6736 & 0.6533 \\
\hline 6 & 0.3243 & 0.880 \\
\hline 7 & 0.4585 & 0.8689 \\
\hline 8 & 0.0000 & 0.6966 \\
\hline 9 & 0.3205 & 1.0000 \\
\hline
\end{tabular}

Table7. Grey relation coefficient

\begin{tabular}{|c|c|c|}
\hline S.No & MRR & SR \\
\hline 1 & 0.4670 & 0.4258 \\
\hline 2 & 0.3706 & 0.4428 \\
\hline 3 & 0.3333 & 1.0000 \\
\hline 4 & 0.4077 & 0.3962 \\
\hline 5 & 0.4261 & 0.4335 \\
\hline 6 & 0.6066 & 0.3608 \\
\hline 7 & 0.5216 & 0.3652 \\
\hline 8 & 1.0000 & 0.4179 \\
\hline 9 & 0.6094 & 0.3333 \\
\hline
\end{tabular}

Table8. Grey relation Grade (GRG)

\begin{tabular}{|c|c|}
\hline S.No & GRG \\
\hline 1 & 0.4464 \\
\hline 2 & 0.4067 \\
\hline 3 & 0.6667 \\
\hline 4 & 0.4019 \\
\hline 5 & 0.4298 \\
\hline 6 & 0.4837 \\
\hline 7 & 0.4434 \\
\hline 8 & 0.7089 \\
\hline 9 & 0.4714 \\
\hline
\end{tabular}

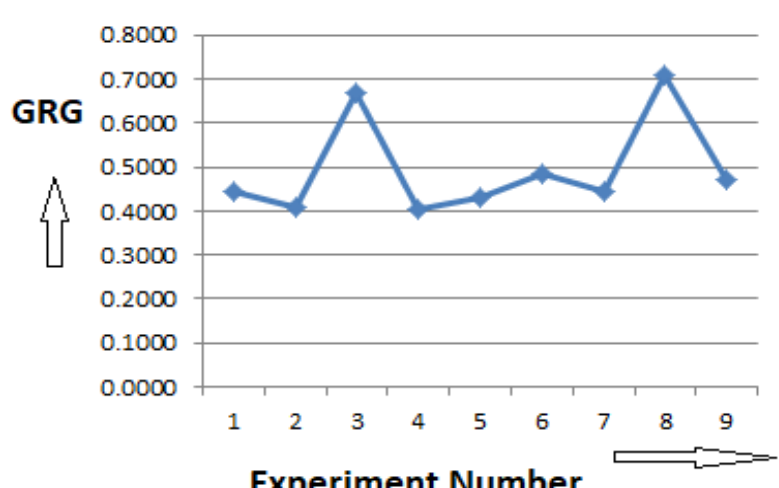

Fig2. Graph of GRG vs. Experiment Number

After getting GRG, the experiment number which is having higher value of GRG represents the optimum values of selected input process parameters. In this work higher value of GRG is occurring 
at eighth experiment and the value of GRG is given by 0.7089 . The predicted optimum values are given in Table 9.

Table9. Predicted Optimum Condition

\begin{tabular}{|c|c|c|c|}
\hline S.No & Parameters & Level & Optimum values \\
\hline 1 & Stand-of distance $(\mathrm{mm})$ & 3 & 3 \\
\hline 2 & Traverse speed $(\mathrm{mm} / \mathrm{min})$ & 2 & 76 \\
\hline 3 & Abrasive flow rate $(\mathrm{g} / \mathrm{min})$ & 1 & 300 \\
\hline
\end{tabular}

\section{CONCLUSION}

This paper presents effect of parameters like stand-off distance, traverse speed and abrasive flow rate on MRR, SR in AWJM of H13 hot die tool steel. Multi-objective grey analysis, along with Taguchi method was employed. The recommended parametric combination for maximization of MRR and minimization of SR is Stand-off distance-3mm, Traverse speed-76mm/min Abrasive flow rate$300 \mathrm{~g} / \mathrm{min}$.

\section{REFERENCES}

[1] Grellier, A.; Siaut, M, "A new hot work tool steel for high temperature and high stress service conditions," 6th, International Tooling Conference-2002, Paris, France

[2] Thilak.M, Anandan A, Arockia George G, Elangovan A, Karthikeayan S, "Optimization of Machining Process Parameters in Abrasive Water Jet Machining," International Journal of Innovative Research in Science, Engineering and Technology Vol. 5, Special Issue 8, May 2016, 221-228

[3] Farhad Kolahan, A. Hamid Khajavi, "Modeling and Optimization of Abrasive Waterjet Parameters using Regression Analysis," World Academy of Science, Engineering and Technology International Journal of Mechanical, Aerospace, Industrial, Mechatronic and Manufacturing Engineering Vol:3, No:11, 2009

[4] Parthiban, S. Sathish and M. Chandrasekaran, "Optimization of Abrasive Water Jet Cutting Parameter for AISI 316L Stainless Steel Sheet," Journal of Applied Fluid Mechanics, Vol. 10, Special Issue, pp. 15-22, 2017.

[5] K. S. Jai Aultrin and M. Dev Anand "Experimental Investigations and Prediction on MRR and SR of Some Non Ferrous Alloys in AWJM Using ANFIS” Indian Journal of Science and Technology, 2 Vol 9 (13), April 2016

[6] Zoran Jurkovic, Mladen Perinic, Sven Maricic "Application of Modelling and Optimization Methods in Abrasive Water Jet Machining," 16th International Research/Expert Conference"Trends in the Development of Machinery and Associated Technology" TMT 2012, Dubai, UAE, 10-12 September 2012

[7] Mayur C. Patel, Mr. S. B. Patel, Mr. R.H. Patel, "Parametric Analysis of Abrasive Water Jet Machining of Aluminium 6351 T6," International Journal For Technological Research In Engineering Volume 1, Issue 12, August-2014

[8] M. A. Azmir, A.K. Ahsan, A. Rahmah, M.M. Noor and A.A. Aziz "Optimization of Abrasive Waterjet Machining Process Parameters using Orthogonal Array With Grey Relational Analysis," Regional Conference on Engineering Mathematics, Mechanics, Manufacturing \& Architecture (EM3ARC) 2007, pp $21 \sim 30$

Citation: Naidu Naresh Kumar, et.al (2019)" Optimization of Process Parameters of Abrasive Water Jet Machining (AWJM) on H13 Hot Die Tool Steel by Grey Relational Analysis", International Journal of Modern Studies in Mechanical Engineering, 5(1), pp. 41-47. DOI: http://dx.doi. org/10.20431/24549711.0501004

Copyright: () 2019 Authors, This is an open-access article distributed under the terms of the Creative Commons Attribution License, which permits unrestricted use, distribution, and reproduction in any medium, provided the original author and source are credited. 